\title{
A Survey of Contact Lens Wearers and Eye Care Professionals on Satisfaction with a New Smart-Surface Silicone Hydrogel Daily Disposable Contact Lens
}

\section{Timothy Grant (D) \\ Anson Tang}

Alcon Laboratories (Australia) Pty Ltd, Macquarie Park, NSW, Australia
This article was published in the following Dove Press journal: Clinical Optometry

\begin{abstract}
Purpose: To assess the patient and ECP preference of verofilcon A lenses over approximately a one-week period when worn on a daily wear, daily disposable (DD) basis by current DD contact lens wearers (CLWs) and new CLWs. ECPs assessed the lens fit, performance on eye and lens preference (to habitual DD lens) for current wearers.

Methods: A total of 218 current DD CLWs and 129 new CLWs aged >18 years participated in the survey. Baseline demographics and one-week data were obtained by 31 ECPs after fitting up to 10 current and 10 new wearers each. The survey was conducted online for both the participants and the ECPs. The survey took place in Australia and New Zealand from April to May 2019.
\end{abstract}

Results: For new wearers, the surveyed results demonstrated strong wearer preference for the verofilcon A lens with quality of life as a main driver. For current wearers, comfort was the main driver for verofilcon A preference. Post survey, $73 \%$ of ECPs stated they would most likely continue to fit verofilcon A lenses.

Keywords: verofilcon A, silicone hydrogel, daily disposable, surface, comfort

\section{Background}

Verofilcon A (PRECISION1 ${ }^{\mathrm{TM}}$ ) is a silicone hydrogel (SiHy) contact lens made from a new high $\mathrm{Dk}\left(90 \times 10^{-11}\right.$ barriers) material with a lubricious 2-3 micron thick surface with more than $80 \%$ water content. ${ }^{1}$ The centre oxygen transmissibility $(\mathrm{Dk} / \mathrm{t})$ of the lens is 100 barrers/cm making it one of the highest oxygen transmissible lenses currently available to Eye Care Practitioners ${ }^{1}$ (ECPs). The high water content surface using SMARTSURFACE ${ }^{\text {TM }}$ Technology is designed to enhance comfort and support an optically precise tear film. ${ }^{1}$ A stable intact tear film is crucial to good subjective vision and comfort. ${ }^{2}$ Verofilcon A has a modulus of $0.6 \mathrm{MPa}$ and has been optimized through the thickness profile to assist ease of handling. ${ }^{1}$

\section{Introduction}

CLWs and ECPs have benefited from two major developments in contact lens technology, and their eventual confluence. Daily disposable (DD) contact lenses offer excellent hygiene and convenience. They are also independent of the use of preservatives necessary to disinfect multi-use contact lenses. ${ }^{3}$ The use of daily
Correspondence: Timothy Grant Alcon Laboratories (Australia) Pty Ltd, Suite 7.0I, Building D, I5 Talavera Rd, Macquarie Park 2II3, NSW, Australia Email tim.grant@alcon.com 
disposable contact lenses reduces the chances of infiltrative events by a factor of 12 when compared with reusable soft contact lenses. ${ }^{3}$ Silicone hydrogel ( $\mathrm{SiHy}$ ) materials are the fastest growing segment of the category ${ }^{4}$ and elevate oxygen availability for soft contact lenses to enable normal corneal physiology and maintenance of physiological integrity beneath the lenses.

Consumers who are new to contact lenses are looking to improve their lifestyle and quality of life, but tend to have concerns regarding their abilities to handle and care for the lenses. ${ }^{5}$ Early experience with contact lenses can be an emotional roller coaster of highs and lows, and support from the ECP during this initial phase may increase the chance of success through advice and support. Existing wearers are more likely to be looking for an upgrade, which will improve their wearing experience by enhancing vision and/or comfort.

Nine out of ten ECPs agree SiHy contact lenses are the best choice to safeguard patients' eye health and should be the first material of choice for DD lenses. ${ }^{6}$ However, they consider the cost of DD SiHy lenses to be a significant barrier to wear, but agree that if costs were equivalent to hema, they would choose SiHy over hema for their DD contact lens fits. ${ }^{6}$ Yet in 2017, approximately $20 \%$ of DD fits were reported to be in hema materials. ${ }^{7}$ Interestingly, $68 \%$ of CLWs expect their ECP to recommend the best option for their eyes, irrespective of the cost. $^{6}$

Fitting behaviours vary considerably between countries. Denmark, Finland and Australia fit the highest proportion of DD lenses of any material at $62 \%, 56 \%$ and $56 \%$, respectively, with the USA somewhere in the middle at 23\% and Mexico, China and Argentina at around 5\%, $6 \%$ and $11 \%{ }^{8}$ Within the leaders, however, the split between the SiHy and hydrogel varies - Finland, Australia and the USA favour SiHy with a hydrogel: SiHy ratio of 4\%:52\% (Finland), 11\%:45\% (Australia) and $4 \%: 19 \%$ (USA), whereas Denmark is firmly planted in the hydrogel camp at $47 \%: 15 \%{ }^{9}$

A persistent issue with fitting new CLWs is between $20 \%$ to $25 \%$ will discontinue wear within the first year. ${ }^{9}$ Of these, $41 \%$ discontinue because of problems with vision, $36 \%$ because of discomfort and $25 \%$ because of handling issues. This 2017 finding is at variance with previous studies, which found discomfort to be the primary reason for discontinuation. $^{10,11}$ Possible explanations could be that improvements in contact lenses have led to better comfort, or perhaps there is a higher proportion of toric and multifocal lens wearers, who are more likely to experience visual difficulties. Furthermore, a primary reason people drop out of contact lenses in the first three months of wear is due to difficulties with application and removal of the lenses. ${ }^{5}$ Practices can counter handling difficulties by instigating better follow-up strategies in the early stages of wear to ensure patients are coping, and by providing resources to help them when the practice is unavailable; for instance in the early mornings and late evenings when they are alone applying and removing their lenses.

Verofilcon A daily disposable contact lenses

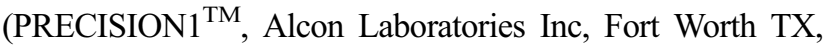
USA) combine high oxygen transmissibility with a new and unique surface technology to provide a high-specification entry-level DD SiHy lens for both new consumers and CLWs who would like to try a different lens. The $51 \%$ water content material has a Dk of 90 , and the lens has a central Dk/t of 100 barrers $/ \mathrm{cm}$ at $-3.00 \mathrm{D},{ }^{1}$ nearly three times the Harvitt and Bonanno requirement for daily wear. ${ }^{12}$ The lens material is encapsulated in an integral, uniform, 2-3 micron-thick SMARTSURFACE ${ }^{\mathrm{TM}}$ with a greater than $80 \%$ water content to maintain a stable pre-lens tear film. ${ }^{1}$

To examine the preference of verofilcon A in realworld conditions, a survey was conducted with ECPs and both new and existing CLWs in Australia and New Zealand.

\section{Materials and Methods}

Three hundred and forty seven participants completed the online survey. They were fitted by 31 ECPs with at least one year's experience fitting contact lenses. On average each ECP fitted 4 new wearers and 7 existing single vision soft CLWs with verofilcon A contact lenses. Participants had to be 18 years or older and have correctable visual acuity of at least $6 / 9$ with their habitual correction and CLWs had to be able to wear contact lenses for at least 8 hours a day for a week. New contact lens wearers had to have correctable visual acuity of at least $6 / 9$ with an up to date spectacle vertex corrected prescription. Participants with ocular or systemic disease were excluded, as were any using prescription or OTC medicines. Contact lens rewetting drops were allowed both prior to and during the evaluation period. Table 1 shows their gender and age demographic and Table 2 shows the percentages breakdown based on the habitual lens brand for the CLW group.

ECPs completed an online survey at baseline and another at the end of the trial period. Similarly, each participant completed an online baseline survey before 
Table I Demographics of the Participants. New Wearers Were Younger Than the Existing wearers, Reflecting existing wearers Had Been Wearing Contact Lenses for a Period of Time Before the Survey

\begin{tabular}{|l|l|l|l|}
\hline Base & $\begin{array}{l}\text { Total } \\
(\mathbf{3 4 7})\end{array}$ & $\begin{array}{l}\text { New Wearers } \\
(\mathbf{1 2 9 )}\end{array}$ & $\begin{array}{l}\text { Current Wearers } \\
\mathbf{( 2 1 8 )}\end{array}$ \\
\hline $\begin{array}{c}\text { Gender } \\
\text { Male }\end{array}$ & $36 \%$ & $43 \%$ & \\
Female & $64 \%$ & $57 \%$ & $32 \%$ \\
\hline Age & & & $68 \%$ \\
I8-24 & $27 \%$ & $39 \%$ & \\
$25-34$ & $39 \%$ & $36 \%$ & $19 \%$ \\
$35-44$ & $18 \%$ & $12 \%$ & $42 \%$ \\
$45-54$ & $10 \%$ & $9 \%$ & $21 \%$ \\
$>1=55$ & $6 \%$ & $4 \%$ & $10 \%$ \\
\end{tabular}

Table 2 Percentages of Previously Worn Lenses by the CLW Group

\begin{tabular}{|c|c|}
\hline \multicolumn{2}{|c|}{ Habitual Contact Lenses Worn by CLWs } \\
\hline I-Day Acurue^ Oasys & $29 \%$ \\
\hline I-Day Acuvuê Moist & $24 \%$ \\
\hline I-Day Acuvue^ TruEye & $9 \%$ \\
\hline DAILIES $^{\circledR}$ AquaComfort Plus ${ }^{\circledR}$ & $15 \%$ \\
\hline MyDay^ & $14 \%$ \\
\hline Biotrue ${ }^{\wedge}$ NE day & $7 \%$ \\
\hline Clariti $^{\wedge}$ I Day & $4 \%$ \\
\hline Proclear^ I Day & $4 \%$ \\
\hline
\end{tabular}

Note: ${ }^{\wedge}$ Trademarks belong to their respective owners.

fitting, and another after they had worn the lenses for at least one week, at the review consultation.

Institutional review board or ethics committee approval was not required as this research was conducted as a market research survey. The research was conducted by ECPs who agreed not to intervene or change the patient's normal standard of care, to protect patient's confidentiality, and to report adverse events encountered during the course of the survey.

All participants were asked to read a Patient Information and Informed Consent Form, at the beginning of the online survey and provided their consent by clicking a check box in the online survey. A printed copy of the informed consent was provided when requested. Patients were apprised of their rights, as per the National Privacy Policy, and advised any adverse events in the course of the research would be reported to the relevant authorities. Kantar Health Australia is bound by the principles of the Australian Market and Social Research Society's Code of Professional Behaviour which govern the collection, retention, use, disclosure and transfer of information about subjects of, and participants in market and social research.

\section{Results}

\section{Consumer Experience New to Contact Lens Wear}

As the new wearers did not have previous contact lens experience for comparison, their preferences reflected improvements in their day-to-day quality of life. Participants were offered a range of statements from which they could choose multiple options. They preferentially selected statements which reflected better control, being able to do things more productively, increased quality of life and less disruption in their daily life.

From the 129 new wearers (Figure 1), 91\% agreed with the statement PRECISION1 "provides me with an option to be spectacle-free", 79\% agreed with the statement "is a great lens to start my contact lens wearing experience" and $70 \%$ agreed with the statement that PRECISION1 "is the one I will continue to wear in the future". These responses were particularly strong in the $18-24$ age group $(n=50)$ with $94 \%$ agreeing the lens provided a spectacle-free option, 90\% agreeing it was a great lens to start their contact lens journey and 78\% agreeing they would continue to wear the lens in the future.

For the new CLWs reported in Figure 2 seventy five percent $(75 \%)$ agreed that the lenses allow them to comfortably wear lenses all day long, 78\% agreed that they provide clear vision at the end of the day as much as at the beginning and $79 \%$ agreed that they had clear vision when looking at digital devices.

When placing lenses on the eye $82 \%$ of new wearers agreed the lenses are easy to place on the eye and $72 \%$ agreed they are easy to remove.

\section{Existing Contact Lens Wearers}

Of the 172 existing CLWs (Figure 3) with a preference when compared to their previous contact lens wearing experience 4 out of $5(81 \%)$ expressed a preference or strong preference for the verofilcon A contact lenses. The preference was more pronounced for people above 25 years, at $80 \%$ or more, and strongest in the 35-44 year-old group at 89\%.

The preferences were related to a comparative experience with their habitual lenses influenced by attributes such as longlasting comfort (Figure 4), less feeling of dryness, all-day comfort and a longer wearing time. Overall, existing wearers still made holistic evaluations such as less disruption in daily life and a better quality of life, but these were secondary to the comparative evaluations and less emphatic than in the nonwearing group. 


\section{Prefer PRECISION1 ${ }^{\mathrm{TM}}$}

Provides me with an option to be spectacle free

Is a great lens to start my contact lens wearing experience

Is the one I will continue to wear in the future

\section{\% new wearers who believe PRECISION1 ${ }^{\mathrm{TM}}$}

\section{$91 \%$}

\section{$79 \%$}

\section{$70 \%$}

Figure I Overall 91\% of new CLWs agreed that verofilcon A contact lens provide an option to be spectacle-free. Note: New Wearers (amongst all new wearers $n=129$ ).

\section{Experience with PRECISION1 ${ }^{\mathrm{TM}} \%$ new wearers who believe PRECISION1 ${ }^{\mathrm{TM}}$}

\section{Provide clear vision at end of the day as much as at the beginning of the day \\ Provide clear vision while I am looking at digital devices such as mobile phone, computer screen, etc.
Allows me to comfortably wear contact lenses all day long

Are easy to remove at the end of the day

Are easy to place on my eye

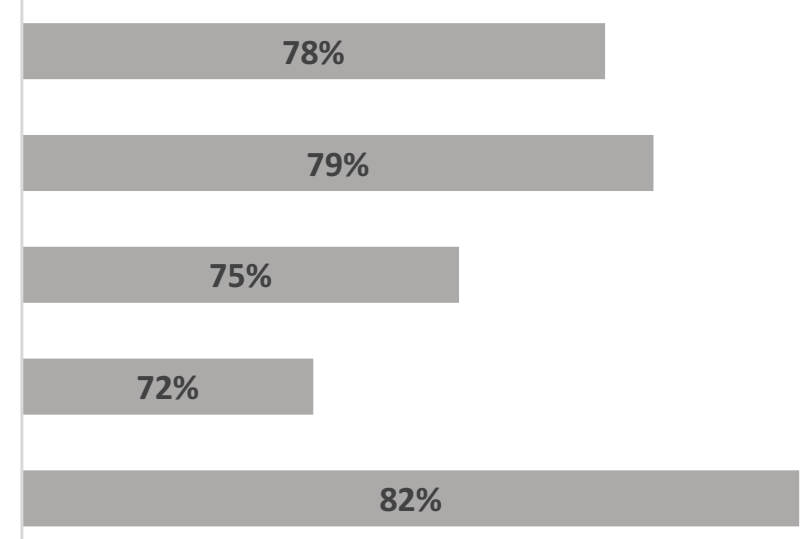

Figure $282 \%$ of new CLWs agreed verofilcon A are easy to place on the eye and $72 \%$ agreed they are easy to remove at the end of the day. Notes: New Wearers (amongst all new wearers $n=129$ ). Data from Grant and Tang. ${ }^{13}$

Current wearers - Patient preference for "comfort" attributes amongst wearers who have a preference after trialling PRECISION1 ${ }^{\mathrm{TM}}$ (Figure 4).

For ease of application and removal, CLWs preferred verofilcon $A$ over their previous lenses at $71 \%$ and $61 \%$, respectively. Preference for visual performance compared to habitual lenses (Figure 5) also favoured the new verofilcon A lens at $85 \%$, with $83 \%$ also preferring them for their performance at the end of the day compared with the beginning.

Current wearers - Patient preference for "consistent \& precise vision" attributes amongst wearers who have a preference after trialling PRECISION1 ${ }^{\mathrm{TM}}$ (Figure 5).

\section{Eyecare Professionals Experience}

More than half of ECPs involved in the trial switched their most preferred contact lens brand to verofilcon A contact lenses
(Figure 6). The ECPs selected the following statement "Makes me feel confident that I recommend the best contact lens brand to my patients" as the main driver for this preference.

\section{Discussion}

In real-world conditions of use, a majority of surveyed new CLWs had a strongly favourable impression of wearing verofilcon A contact lenses, agreeing the lenses improved their quality of life. The most notable benefits of verofilcon A to new wearers are clear distance vision, comfortable fit, ease of insertion, longlasting comfort and comfort when looking at a mobile phone or computer. New wearers also agreed verofilcon A contact lenses were a great way to start their contact lens wearing experience and would stay wearing them. Lifestyle improvements are important points for practitioners to incorporate into discussions with potential CLWs. 


\section{Patient preference post PRECISION1 ${ }^{\mathrm{TM}}$ experience}

current wearers who have a preference after trialling PRECISION1 ${ }^{\mathrm{TM}}$

\begin{tabular}{|c|c|c|c|}
\hline Overall & $N=172$ & $81 \%$ & $19 \%$ \\
\hline $18-24$ y. $о$. & $\mathrm{N}=35$ & $72 \%$ & $29 \%$ \\
\hline 25 - 34 y. o. & $N=66$ & $82 \%$ & $19 \%$ \\
\hline 35 - 44 y. o. & $N=37$ & $89 \%$ & $11 \%$ \\
\hline 45 - 54 y. o. & $\mathrm{N}=19$ & $84 \%$ & $16 \%$ \\
\hline$\geq 55$ у. $о$. & $N=15$ & $80 \%$ & $20 \%$ \\
\hline
\end{tabular}

$88 \%$

"Feel comfortable from the time I put them in until I want to take them out"

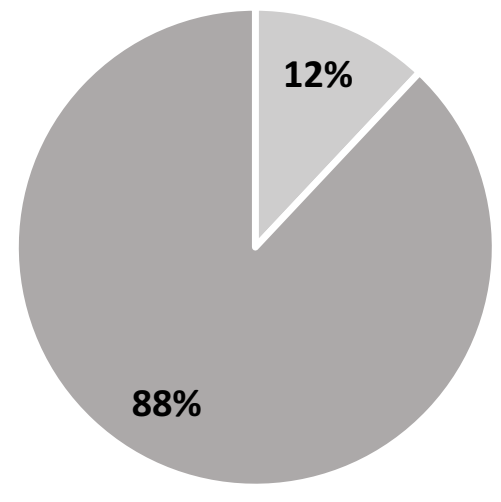

- Prefer / Strongly prefer PRECISION1 ${ }^{\mathrm{TM}}$ contact lenses
86\% "Provides me with

long lasting comfort"

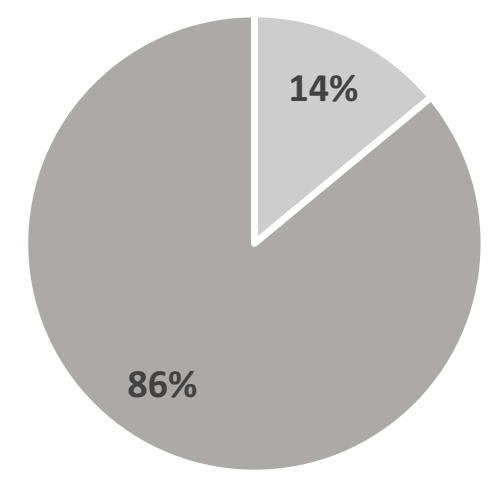

- Prefer / Strongly prefer PRECISION1 ${ }^{\text {TM }}$ contact lenses

Figure 4 Existing wearers' comfort preferences.

Existing CLWs who were switched into verofilcon A lenses also expressed strong positive feedback on their performance with 4 out of 5 preferring the verofilcon A lenses to their previous lenses. As they already had experience of contact lens wear, the feedback in the survey was comparative in nature, with strong preferences for verofilcon A lenses because of subjective comparison to their previous lenses such as longer 
85\% "Provide consistent and precise

vision from beginning of the day to when I wnat to remove them at the end of the day

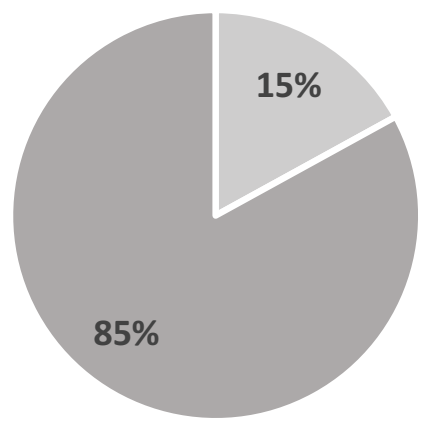

- Prefer / Strongly prefer PRECISION1 ${ }^{\text {TM }}$ contact lenses

Figure 5 Existing wearers' vision preference compared to their habitual vision.

\section{Pre PRECISION ${ }^{\mathrm{TM}}$ trial}

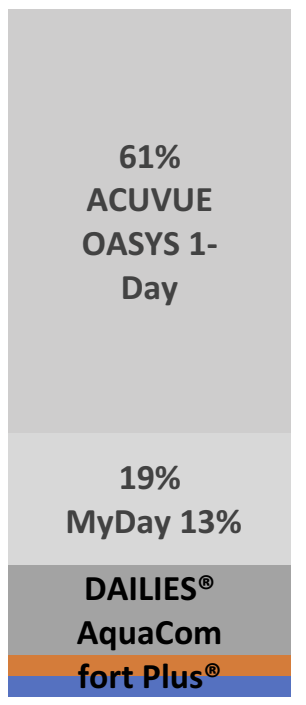

$83 \%$ "Provide clear vision at the end of the day as much as at the beginning of the day"

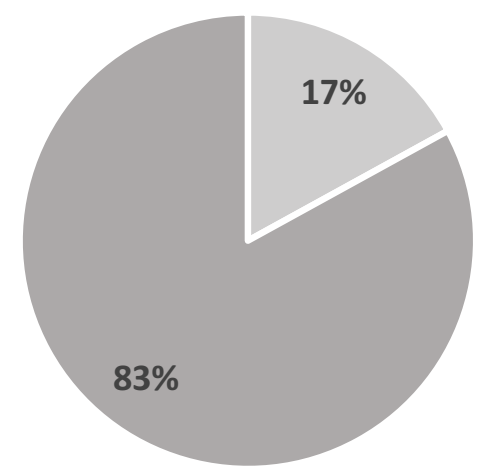

- Prefer / Strongly prefer PRECISION1 ${ }^{\text {TM }}$ contact lenses

\section{Post PRECISION1 ${ }^{\text {TM }}$ trial}

Figure 6 More than half of ECPs surveyed changed from their previously most preferred lens type to verofilcon A. Note: ECPs most preferred $(n=31)$.

lasting comfort. Based on these results, the lenses may be a good option for people who experience intermittent discomfort and/or end of day discomfort with their existing lenses which is often tolerated, but not appreciated. Switching to verofilcon A contact lenses offer a chance to address this, knowing comfort is one of the main reasons of contact lens drop out, ${ }^{11}$ as well as significantly improving oxygen supply for hydrogel wearers with these symptoms and other hypoxic effects such limbal redness. ${ }^{14}$ 
As might be expected from a lens positively received by both new and existing CLWs, ECPs expressed enthusiasm and a preference to continue to fit it, many adopting it as their preferred daily disposable lens. It offers a credible option to move CLWs into SiHy DD lenses as a first and preferred option for ECPs and contact lens wearers.

\section{Conclusions}

Verofilcon A contact lenses are a high-quality SiHy DD option aimed at consumers who are new to contact lens wear including current spectacles wearers as well as those upgrading to DD from hema or frequent replacement lens wear. A one-week trial resulted in strong preferences to proceed with the lenses by both new CLWs, current CLWs and by the ECPs who fitted them. With the ease of placing and removal, the $>80 \%$ water surface moisture, ${ }^{1}$ high oxygen transmissibility, and the highly wettable, high water content SMARTSURFACETM, verofilcon A contact lenses open up an excellent option to these consumers and practitioners.

\section{Acknowledgments}

This survey was sponsored by Alcon Laboratories Inc. (Fort Worth TX, USA). The survey was managed, conducted and data analysis was conducted by Kantar Health Australia funded by Alcon Laboratories. Medical writing support, which was funded by Alcon Laboratories Inc. was provided by Toolbox (Zurich, Switzerland). The authors would like to thank all the survey participants.

\section{Disclosure}

Timothy Grant and Anson Tang are employees of Alcon Laboratories (Australia) Pty Ltd. The authors report no other conflicts of interest in this work.

Clinical Optometry

\section{Publish your work in this journal}

Clinical Optometry is an international, peer-reviewed, open access journal publishing original research, basic science, clinical and epidemiological studies, reviews and evaluations on clinical optometry. All aspects of patient care are addressed within the journal as well as the practice of optometry including economic and business analyses. Basic and clinical research papers are published that cover

Submit your manuscript here: https://www.dovepress.com/clinical-optometry-journal

\section{References}

1. Tyler's quarterly soft contact lens parameter guide. Tyler's $Q$ soft contact lens Param Guid. Sep 2019.

2. Willcox MDP, Argüeso P, Georgiev GA, et al. The ocular surface TFOS DEWS II tear film report. Ocul Surf. 2017;15(3):366-403. doi:10.1016/j.jtos.2017.03.006

3. Chalmers RL, Keay L, McNally J, Kern J. Multicenter case-control study of the role of lens materials and care products on the development of corneal infiltrates. Optom Vis Sci. 2012;89(3):316-325. doi:10.1097/OPX.0b013e318240c7ff

4. Morgan PB, Woods CA, Tranoudis IG, et al. International contact lens prescribing in 2017. Cont Lens Spectr. 2018;33:28-33.

5. Sulley A, Young G, Hunt C. Factors in the success of new contact lens wearers. Cont Lens Anterior Eye. 2017;40(1):15-24. doi:10.1016/j.clae.2016.10.002

6. Orsborn G, Dumbleton K. Eye care professionals' perceptions of the benefits of daily disposable silicone hydrogel contact lenses. Cont Lens Anterior Eye. 2019;42:373-379. doi:10.1016/j. clae.2019.02.012

7. Nichols JJ. Contact lenses 2017. Cont Lens Spectr. 2018;33:20-25.

8. Morgan PB, Woods CA, Tranoudis JG, et al. International contact lens prescribing in 2018. Cont Lens Spectr. 2019;26-32.

9. Sulley A, Young G, Hunt C, McCready S, Targett MT, Craven R. Retention rates in new contact lens wearers. Eye Cont Lens. 2017. doi:10.1016/j.clae.2016.10.002

10. Pritchard N, Fonn D, Brazeau D. Discontinuation of contact lens wear: a survey. Cont Lens Ant Eye. 1999;26(6):157-162. doi:10.1016/S0892-8967(01)00040-2

11. Schlanger JL. A study of contact lens failures. J Am Optom Assoc. 1993;64(3):220-224.

12. Harvitt DM, Bonanno JA. Re-evaluation of the oxygen diffusion model for predicting minimum contact lens $\mathrm{Dk} / \mathrm{t}$ values needed to avoid corneal anoxia. Optom Vis Sci. 1999;76(10):712-719. Available from: . doi:10.1097/00006324-199910000-00023

13. Grant T, Tang A. New Contact Lens Wearers and Practitioners Have High Patient Satisfaction with a Novel SmartSurface Technology Daily Disposable contact lens at International Cornea \& Contact Lens Congress. Noosa, Australia: Poster; Oct 2019.

14. Papas EB, Vajdic CM, Austen R, Holden BA. High-oxygentransmissibility soft contact lenses do not induce limbal hyperaemia. Curr Eye Res. 1997;16(9):942-948. doi:10.1076/ceyr. 16.9.942.5049 all aspects of optics, refraction and its application to the theory and practice of optometry. The manuscript management system is completely online and includes a very quick and fair peer-review system, which is all easy to use. Visit http://www.dovepress.com/ testimonials.php to read real quotes from published authors. 